\title{
Unruptured giant left ventricular pseudoaneurysm after silent myocardial infarction
}

\author{
Rajeev Bhardwaj, ${ }^{1}$ Sachin Sondhi, ${ }^{1}$ Ayushi Mehta ${ }^{2}$
}

${ }^{1}$ Department of Cardiology, Indira Gandhi Medical College, Shimla, Himachal Pradesh, India ${ }^{2}$ Department of Anaesthesia, Indira Gandhi Medical College, Shimla, Himachal Pradesh, India

\section{Correspondence to Dr Sachin Sondhi, ssachin119@gmail.com}

Accepted 26 June 2018

\section{DESCRIPTION}

An 88-year-old woman presented with complaints of class 2 dyspnoea for the last 6 months with episodes of paroxysmal nocturnal dyspnoea. Except for her age, she had no other risk factor for coronary artery disease. On cardiovascular examination, she had double apical impulse with a pan-systolic murmur at the apex and her ECG showed Q waves in inferior leads. She had one episode of resting typical chest pain 2 years back for which she did not seek medical consultation; afterwards, she never experienced angina pain.

Transthoracic echocardiography revealed giant aneurysm involving the lateral wall of the left ventricle (figure 1, videos 1 and 2). The ratio of the maximum diameter of the orifice to the maximum internal dimensions of the aneurysmal cavity was less than 0.5 (figure 2). There was large clot in the aneurysm involving the posterior wall of the left ventricle (figures 3 and video 2). The colour flow signals across the neck of aneurysm showed bidirectional flow (figure 4) and moderate mitral regurgitation (figure 5). The basal septum was akinetic and the posterior wall was dyskinetic (video 2) and left ventricular ejection fraction was 20\%-25\%. She was started on ecosprin, rosuvastatin, metoprolol, remipril, spironolactone and torsemide and was advised to undergo surgery.

Left ventricular pseudoaneurysm is a rare complication seen after myocardial infarction (MI). The left ventricular free wall rupture (LV FWR) in this thrombolytic era is seen only in $0.5 \%$ of cases and carries a substantial mortality of $20 \% .^{1}$ The FWR is seen either within 48 hours or within 2 weeks of acute MI. The LV FWR causes sudden cardiac death, but sometimes rupture of a ventricular free

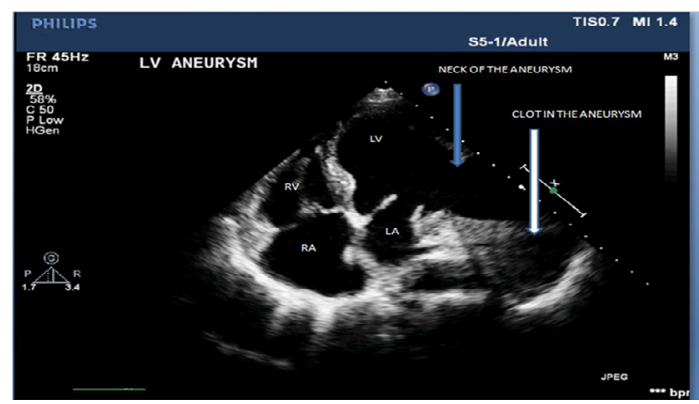

Figure 1 Transthoracic echocardiogram, apical fourchamber view showing a large aneurysm in the lateral wall of the left ventricle (LV), the neck of the aneurysm (blue arrowhead) and clot in the cavity of the aneurysm (white arrowhead). LA (left atrium), LV (left ventricle), RA (right atrium), RV (right ventricle).

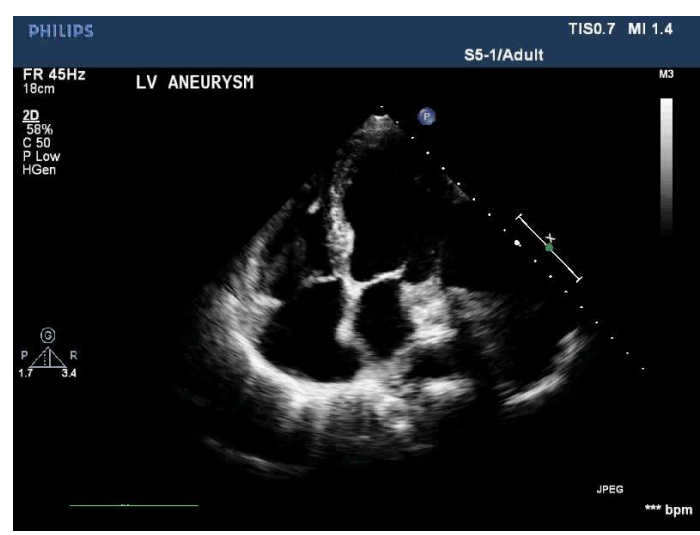

Video 1 Transthoracic echocardiogram, apical fourchamber view showing a large pseudoaneurysm involving the lateral wall and hypokinetic basal septum.

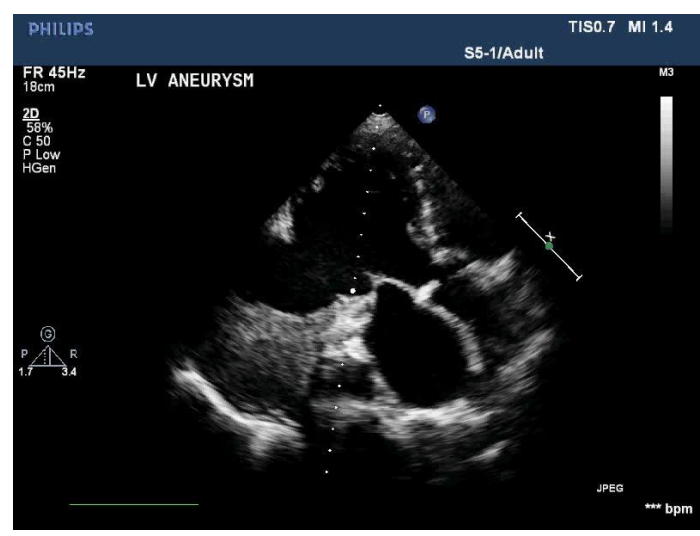

Video 2 Transthoracic echocardiogram, apical threechamber view showing thinned out akinetic basal septum and dyskinetic posterior wall and large pseudoaneurysm involving the posterior wall with a clot inside it.

wall is contained by overlying adherent pericardium resulting in pseudoaneurysm formation. The pseudoaneurysm lacks myocardial tissue and communicates with the cavity of the left ventricle by a narrow neck, whose diameter is less than $50 \%$ of the maximum internal dimensions of an aneurysm ${ }^{2}$ with more ragged edges and turbulent bidirectional flow. The risk factors for the development of pseudoaneurysm after MI include advanced age, female gender, hypertension, first transmural MI and lack of collateral circulation. In contrast to pseudoaneurysm, true LV aneurysm develops after MI due to scar thinning and infarct expansion and contains epicardium, myocardium and endocardium and has a wide neck, smooth margins and requires conservative treatment. $^{3}$ 


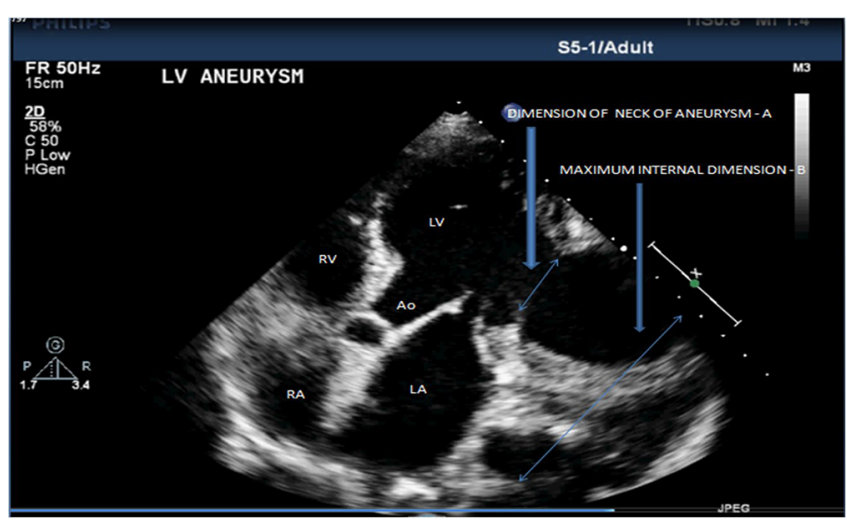

Figure 2 Transthoracic echocardiogram, apical five-chamber view showing a pseudoaneurysm that communicates with the cavity of the left ventricle (LV) by a narrow neck, whose diameter (A) is less than $50 \%$ of the maximum internal dimensions (B) of the aneurysm. LA (left atrium), RA (right atrium), RV (right ventricle).

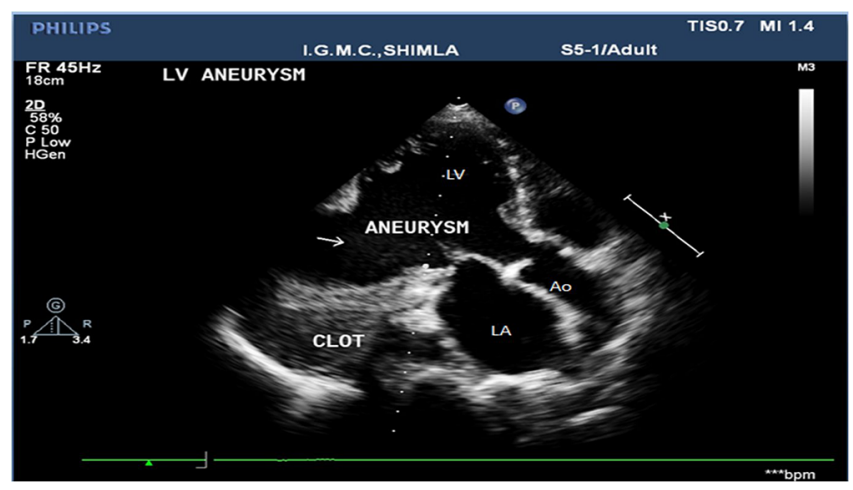

Figure 3 Transthoracic echocardiogram, apical three-chamber view showing pseudoaneurysm involving the posterior wall of the left ventricle (LV) with a large clot inside it. LA (left atrium), Ao (aorta)

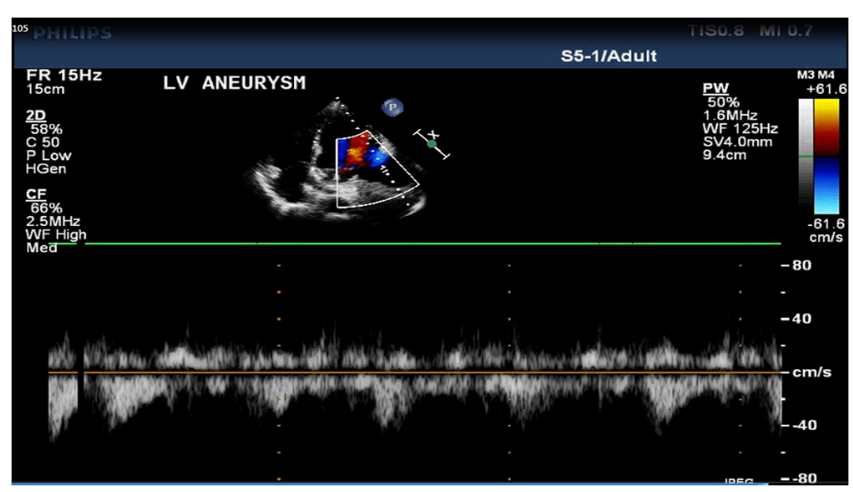

Figure 4 Transthoracic echocardiogram, apical four-chamber view showing colour flow bidirectional signals and continuous-wave Doppler signals in the cavity of the pseudoaneurysm.

The most common location of LV pseudoaneurysm is posterolateral, in contrast to a true aneurysm, which is mostly located in the apicoanterior wall. The usual presentation of LV

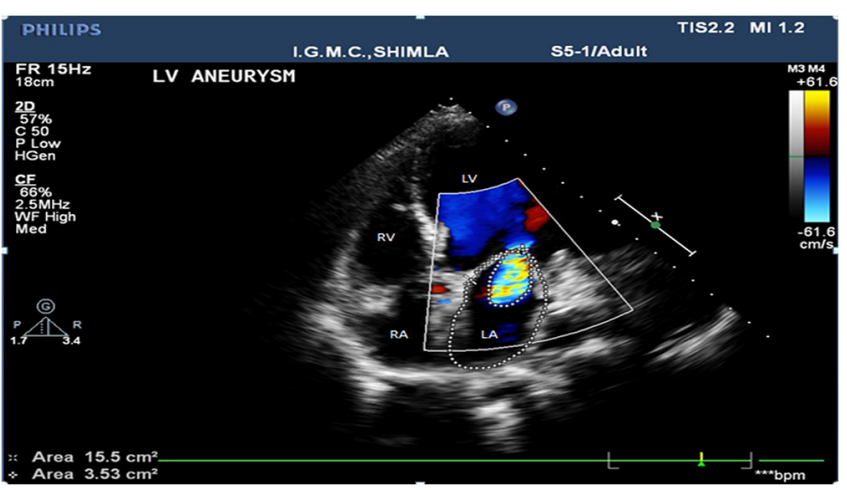

Figure 5 Transthoracic echocardiogram, apical four-chamber view with colour Doppler across the mitral valve demonstrating moderate mitral regurgitation. LA (left atrium), LV (left ventricle), RA (right atrium), RV (right ventricle).

pseudoaneurysm is heart failure, embolism, arrhythmias and sometimes sudden cardiac death due to rupture. Some pseudoaneurysms are surprisingly stable and go undetected for years. Besides 2D echocardiography, contrast echo, CMR or even LV ventriculography are other diagnostic modalities for differentiation of true and false aneurysms. Cardiac CT is another important modality as it is easily accessible, quick and offers high spatial resolution. Because the tendency of LV pseudoaneurysm to rupture is high, early surgical intervention by patch closure or Dor's procedure is recommended. ${ }^{2}$

\section{Learning points}

- Left ventricular (LV) pseudoaneurysm appears more commonly after inferior myocardial infarction.

- Although heart failure, embolism and arrhythmias are common presentations, some aneurysms are surprisingly stable and go undetected for years.

- LV pseudoaneurysm requires differentiation from a true aneurysm; because of the tendency of pseudoaneurysm to rupture, early surgical intervention is recommended.

Contributors RB and SS diagnosed the case. Echocardiography was performed by $\mathrm{RB}$. The manuscript is written by SS and AM. The manuscript is approved by all the authors.

Funding The authors have not declared a specific grant for this research from any funding agency in the public, commercial or not-for-profit sectors.

Competing interests None declared.

Patient consent Obtained.

Provenance and peer review Not commissioned; externally peer reviewed.

\section{REFERENCES}

1 French JK, Hellkamp AS, Armstrong PW, et al. Mechanical complications after percutaneous coronary intervention in ST-elevation myocardial infarction (from APEXAMI). Am J Cardiol 2010;105:59-63.

2 Eren E, Bozbuga N, Toker ME, et al. Surgical treatment of post-infarction left ventricular pseudoaneurysm: a two-decade experience. Tex Heart Inst I 2007;34:47-51.

3 Gatewood RP, Nanda NC. Differentiation of left ventricular pseudoaneurysm from true aneurysm with two dimensional echocardiography. Am J Cardiol 1980;46:869-78. 
Copyright 2018 BMJ Publishing Group. All rights reserved. For permission to reuse any of this content visit http://group.bmj.com/group/rights-licensing/permissions.

BMJ Case Report Fellows may re-use this article for personal use and teaching without any further permission.

Become a Fellow of BMJ Case Reports today and you can:

- Submit as many cases as you like

- Enjoy fast sympathetic peer review and rapid publication of accepted articles

Access all the published articles

Re-use any of the published material for personal use and teaching without further permission

For information on Institutional Fellowships contact consortiasales@bmjgroup.com

Visit casereports.bmj.com for more articles like this and to become a Fellow 